\title{
Na gestualidade de professoras e bebês, o corpo fala de relações ${ }^{1}$
}

\author{
BONFIM, Patrícia Vieira (Niterói, Rio de Janeiro, Brasil) ${ }^{1^{*}}$ \\ OSTETTO, Luciana Esmeralda (Niterói, Rio de Janeiro, Brasil) $)^{2+*}$ \\ ${ }^{1}$ Universidade Federal Fluminense, Programa de Pós-Graduação em Educação, \\ Doutorado em Educação \\ ${ }^{2}$ Universidade Federal Fluminense, Programa de Pós-Graduação em Educação, \\ Faculdade de Educação \\ ORCID ID: http://orcid.org/0000-0002-6989-7034* \\ ORCID ID: https://orcid.org/0000-0002-1948-5090*
}

\begin{abstract}
Resumo
Com o corpo, o indivíduo suspeita o mundo, afeta e é por ele afetado, constrói relações, significa e expressa a existência. O que dizem os conpos de bebês e de adultos em relação? Referenciado sobretudo na Psicologia walloniana e na Antropologia lebretoniana, apresentam-se resultados parciais de pesquisa de doutorado que objetiva analisar narrativas sobre/com o corpo tecidas nas interações entre professoras e bebês. Os dados, advindos da observação de um grupo de bebês com suas professoras, foram gerados mediante registros escritos e fotográficos, focando diferentes momentos da rotina, posteriormente apreciados e discutidos em encontros com as docentes. Para a análise, observaram-se movimentos relacionais compostos por gestos produzidos entre bebês e professoras no ambiente externo à sala de referência. Notou-se preliminarmente que a qualidade da relação estabelecida entre eles foi fundamental para ativar a descoberta do corpo, na experimentação do espaço, das texturas, das formas e dos sabores.
\end{abstract}

Palavras-chave

Corpo. Educação infantil. Creche. Interações adulto-bebês.

\section{In the gestuality of teachers and babies, the body talks of relationships}

\begin{abstract}
With the body, the individual suspects the world, affects and is affected by it, builds relationships, signifies and expresses existence. What do the bodies of babies and adults say about each other? Based mainly on Wallonian Psychology and Lebretonian Anthropology, this article presents partial results of a doctoral research that aims to analyze narratives about/with the body woven in the interactions between teachers and babies. The data, resulting from the observation of a group of babies with their teachers, were generated through written and photographic records, focusing on different moments of the routine, later appreciated and discussed in meetings with the teachers. For the analysis presented here, relational movements composed by the gestures produced between babies and teachers were observed in the environment outside the reference room. It was preliminarily noted that the quality of the relationship established between them was fundamental to activate the discovery of the body, in the experimentation of space, textures, shapes and flavors.
\end{abstract}

\section{Keywords}

Body. Early Childhood Education. Daycare. Adult-baby relationships.

1 A pesquisa conta com recursos financeiros do Programa de Apoio à Qualificação de Servidores (Proaq) do Instituto Federal de Educação, Ciência e Tecnologia (IF) Sudeste de Minas Gerais, campus Muriaé (Edital no 18/2017).

Educação \& Formação, Fortaleza, v. 5, n. 14, p. 115-132, maio/ago. 2020

DOI: https://doi.org/10.25053/redufor.v5i14mai/ago.1647

http://seer.uece.br/redufor 


\title{
Gestos dibujados entre bebés y maestros en la educación de la primera
}

\author{
infancia: aprendizaje corporal ampliado
}

\begin{abstract}
Resumen
Con el cuerpo, el individuo sospecha del mundo, lo afecta y se ve afectado por él, construye relaciones, significa y expresa la existencia. ¿Qué dicen los cuerpos de bebés y adultos el uno del otro? Referenciado principalmente en la Psicología walloniana y la Antropología lebretoniana, este artículo presenta resultados parciales de una investigación doctoral que tiene como objetivo analizar narraciones sobre / con el cuerpo tejidas en las interacciones entre maestros y bebés. Los datos resultantes de la observación de un grupo de bebés con sus maestros se generaron a través de registros escritos y fotográficos, enfocándose en diferentes momentos de la rutina, luego apreciados y discutidos en reuniones con los maestros. Para el análisis presentado aquí, los movimientos relacionales compuestos por los gestos producidos entre los bebés y los maestros se observaron en el entorno fuera de la sala de referencia. Se observó preliminarmente que la calidad de la relación establecida entre ellos era fundamental para activar el descubrimiento del cuerpo en la experimentación de espacios, texturas, formas y sabores.
\end{abstract}

\section{Palabras clave}

Cuerpo. Educación infantil. Guarderías. Interacciones adulto-bebés.

\section{Introdução}

$\mathrm{Na}$ atualidade, a saída dos bebês do meio familiar para frequentarem espaços de cuidado e de educação, como as creches, é cada vez mais notória. Isso se deve, sobretudo à intensificação do processo de urbanização, ao reconhecimento das vantagens da educação infantil para as crianças e à participação crescente de mulheres brasileiras no mercado de trabalho (CAMARANO; KANSO; ALCÂNTRA, 2014). Ainda que as razões para a frequência de bebês à creche sejam múltiplas, certo está que a educação é um direito das crianças definido na Constituição Federal Brasileira de 1988, reafirmado na Lei de Diretrizes e Bases da Educação Nacional de 1996.

Todavia, "[...] quanto menor a renda da população, menor o percentual de crianças matriculadas em creches e pré-escolas, o que revela uma sonegação desse direito justamente àquelas famílias e crianças mais necessitadas desse atendimento" (CAMPOS; CRUZ, 2006, p. 13). Além dessa constatação, há de atentar-se também para a qualidade da educação ofertada, principalmente em relação à dos bebês, considerando que estes são seres muito potentes no que se refere à aprendizagem, 
mas, ao mesmo tempo, corporalmente frágeis diante de propostas educativas equivocadas ou negligentes.

$\mathrm{Na}$ pesquisa que estamos desenvolvendo, temos como objetivo analisar as narrativas sobre/com o corpo tecidas nas relações entre professoras e bebês no cotidiano de uma creche pública mineira. Tal proposta dá visibilidade às interações, um dos eixos a serem considerados no trabalho pedagógico desenvolvido pelas instituições de educação infantil (BRASIL, 2009). Nesse sentido, também coloca em seu horizonte a qualidade da educação de 0 a 3 anos, na medida em que essas interações revelam conceitos, preconceitos, limites e possibilidades dos corpos.

O corpo, elemento central neste trabalho, é abordado em sua inteireza (afetividade, ato motor, inteligência e construção da pessoa) (WALLON, 1975, 2007); dotado de estesia; capaz, assim, de perceber o mundo ao seu entorno por meio dos sentidos - tato, paladar, audição, visão e olfato (LE BRETON, 2012b, 2016; NÓBREGA, 2008). É também portador de linguagem comunicativa e expressiva, definida no contexto de uma dada cultura e sociedade (LE BRETON, 2012a, 2019).

Segundo Le Breton (2012b), os lugares onde se vive interferem diretamente nos processos de sociabilidade humana e de percepção do corpo. Se o tamanho das casas ocidentais, a disposição dos materiais no espaço, os objetos e as paisagens dizem das relações humanas que são ou não cultivadas, não menos importante a considerar é como os corpos se expressam ou se reprimem nos primeiros anos de educação na escola.

A partir desses pressupostos teóricos, a questão-problema que impulsiona a investigação pode ser assim formulada: que narrativas sobre/com o corpo são tecidas na creche considerando-se as interações entre adultos e bebês? Visando encaminhar essa discussão no presente artigo, assim o organizamos: no primeiro momento, apresentamos os pressupostos teóricos que fundamentam nossa concepção de corpo, propondo um diálogo entre dois autores franceses: Henri Wallon (1879-1962), um importante filósofo, médico e psicólogo, e David Le Breton, antropólogo, sociólogo e escritor. No segundo momento, apresentamos o percurso metodológico e as concepções que embasam nosso entendimento em relação à pesquisa de abordagem qualitativa em educação. No terceiro momento, abordamos alguns dados produzidos no percurso. Considerando que a referida pesquisa está em andamento, no quarto e último momento do texto, pontuamos resultados preliminares e destacamos as primeiras contribuições do 
trabalho para a área da educação infantil, em especial para a educação das crianças de 0 a 3 anos nas creches.

\title{
20 mundo (in)corporado nas relações
}

\begin{abstract}
Por meio dos sentidos, suspeitamos o mundo. Com os olhos, nós olhamos a vida. [...] Olhar é fantasiar sobre aquilo que está escondido atrás das coisas. Quando olhamos, nós acordamos alegrias, tristezas, saudades, amores, lembranças, que dormem em nossos corações. Os olhos têm raízes pelo corpo inteiro. (QUEIRÓS, 2009, p. 6-9).
\end{abstract}

O poeta mineiro, em seu livro Os cinco sentidos, provoca-nos a refletir que apreendemos o mundo perceptivamente. Para ele, essa apreensão, por meio da visão, da audição, do olfato, do paladar e do tato, tem raízes mais profundas e extensas, raízes que envolvem o corpo inteiro. Por isso, quando olhamos uma paisagem, por exemplo, podem vir à tona lembranças de lugares longínquos, da voz da pessoa amada, de cheiros e de sabores da infância. Como dissera Le Breton (2009), as reminiscências do corpo/no corpo podem florescer de uma livre associação que vivifica uma história passada.

Poetas e cientistas sinalizam: em cada sentido moram outros sentidos, que despertam fantasias e provocam sonhos. Pelos sentidos, captamos e significamos 0 mundo, fazendo-nos corpos expandidos, corpos reprimidos, corpos fragilizados, corpos ativos. Desse ponto e conforme já anunciado na parte introdutória do texto, para situar de que perspectiva entendemos o corpo, recorremos a uma abordagem interdisciplinar que contempla dois pesquisadores franceses de formação ampla: Henri Wallon e David Le Breton.

Wallon (2007) discute, em suas teorias, que o ser humano, desde a tenra infância, é uma pessoa inteira. Isso pode ser notado em seu conceito de psicogênese da pessoa concreta, que compreende, de forma integrada, os processos que constituem o psiquismo humano: a afetividade, o ato motor (movimento), o conhecimento (ou a inteligência) e a construção da pessoa (ou a construção do Eu).

Para o referido autor, a afetividade é a capacidade que o ser humano tem, desde a tenra idade, de ser afetado, seja pelo mundo interno ou externo. A afetividade engloba a emoção, os sentimentos e a paixão, sendo a emoção a manifestação mais visível da afetividade. É por meio dela, por exemplo, que o bebê humano, desde os primeiros dias 
de vida, se liga ao Outro e se comunica mediante balbucios, choros e movimentos desordenados das mãos e dos pés (WALLON, 2007).

Para ampliar nossa visão sobre as emoções, Le Breton $(2009,2019)$ enfatiza que elas não devem ser estudadas como fenômenos fisiológicos ou psicológicos de forma isolada, embora tais aspectos também sejam importantes para compreendê-las. Com o aporte da Antropologia, as emoções são percebidas como construção social e cultural; por isso, situações como o nascimento de uma criança, a vivência de um luto ou o fracasso em um exame podem variar segundo o repertório do grupo que as vivencia.

Enquanto Le Breton $(2009,2019)$ não trabalha os conceitos de emoção e de sentimento separadamente, Wallon (2007) o faz destacando que, se, por um lado, as emoções transparecem, por outro, os sentimentos são menos perceptíveis; desse modo, ficam reservados no campo da cognição. Isso explica por que as crianças de tenra idade tendem a não conseguir lidar com os processos psíquicos sentimentais que estão em fase de elaboração. Consequentemente:

A criança solicitada pelo sentimento não tem, no tocante às circunstâncias, as reações instantâneas e diretas da emoção. Sua atitude é de abstenção e, caso observe, é como um olhar distante e furtivo que rejeita qualquer participação ativa nas relações que se tecem à sua volta. Tentar provocá-la é deixá-la de mau humor; fica resmungona por falta de aptidão e de gosto pelas trocas improvisadas com o outro. Parece fechar sobre si mesma o circuito de suas impressões; muitas vezes absorta em chupar seu dedo, rumina-as dentro de si mesma. Esse período inicial, defensivo e negativo, só poderá se modificar com o surgimento e o progresso das representações mentais que fornecerão a seus entressonhos motivos e temas mais ou menos inatuais. (WALLON, 2007, p. 126).

Essa explicação contribui para pensarem-se os bebês e as crianças bem pequenas na educação infantil, pois compreender como se estruturam os sentimentos e realizar, sensível e atentamente, uma leitura corporal são atitudes que podem facilitar a interpretação da apatia, que ocasionalmente é interpretada de forma equivocada pela escola como desinteresse da criança por uma atividade.

Considerando que o corpo não é apenas um conjunto afetivo, mas uma unidade que deve ser vivenciada na elaboração dos processos de desenvolvimento e de aprendizagem da criança, essa unidade engloba também o conjunto motor. Em outras palavras, o conjunto que viabiliza as diversas formas de deslocamento:

1. deslocamentos do corpo no tempo e no espaço, em função das leis da gravidade; 2. movimentos voluntários ou intencionais do corpo ou partes dele; 
3. reações posturais que se caracterizam por mímicas e expressões faciais diante das diferentes situações. (ALMEIDA, 2014, p. 597).

O movimento humano inicia-se desde a vida fetal, quando, em torno de aproximadamente quatro meses, a gestante consegue perceber os primeiros deslocamentos mais atuantes da criança no útero. Após o nascimento, o bebê realiza gesticulações espontâneas, que darão suporte ao seu pensamento e que, com o passar do tempo, vão se tornando mais conscientes e coordenadas. Ao refletir sobre as interações nos processos que desencadeiam o movimento humano em cada cultura, Le Breton (2012a, p. 44) enfatiza que a gestualidade

[...] refere-se às ações do corpo quando os atores se encontram: ritual de saudação ou de despedida (sinal de mão, aceno de cabeça, aperto de mão, abraços, beijos no rosto, na boca, mímicas etc.), maneiras de consentir ou de negar, movimentos da face e do corpo que acompanham a emissão da palavra, direcionamento do olhar, variação da distância que separa os atores, maneiras de tocar ou de evitar o contato etc.

Portanto, muito ainda temos de avançar nos estudos que têm como foco os corpos dos bebês e dos adultos em interação, haja vista que existem diferenças significativas e assimétricas que marcam a gestualidade desses dois grupos intergeracionais. Segundo Wallon (2007), a criança pensa se movimentando. Assim sendo, essa última ação não deve ser percebida como indisciplina, mas sim como indispensável ao desenvolvimento infantil e ao conjunto cognitivo que o autor denomina de conhecimento ou inteligência. Para ele, a função da inteligência reside em dois aspectos: definir e explicar, e está indissociavelmente relacionada aos conjuntos motor e afetivo.

Em uma perspectiva que amplia essa visão de perceber o ser humano como um todo indivisível, Le Breton (2009, p. 112) esclarece e justifica seu posicionamento:

Opor 'razão' e 'emoção' seria desconhecer que ambas estão inscritas no seio de lógicas pessoais, impregnadas de valores e, portanto, de afetividade. Existe uma inteligibilidade da emoção, uma lógica que a ela se impõe; da mesma forma, uma afetividade no mais rigoroso dos pensamentos, uma emoção que o condiciona.

Esse referencial teórico tem nos permitido interpretar as imagens dos corpos, de adultos e de bebês como seres inteiros, em seus aspectos afetivos, motores e cognitivos, como assim o fez Wallon (2007) no seu quarto e último conjunto funcional, que ele denominou de "A Pessoa". 


\section{Na mira metodológica: observações, registros escritos e fotográficos, encontros e narrativas}

A partir do objetivo elencado, analisar as narrativas sobre/com o corpo, tecidas nas interações entre professoras e bebês no cotidiano de uma creche pública, optamos por realizar uma pesquisa de abordagem qualitativa, que, segundo Lüdke e André (2013), conduz a uma relação direta e mais prolongada do pesquisador com o ambiente e os sujeitos pesquisados, mais intensamente por meio do trabalho exaustivo de campo. Escolhemos esse tipo de pesquisa também por considerá-la mais adequada, levando em conta os seguintes aspectos apresentados:

\footnotetext{
O processo é mais significativo que o produto. $O$ interesse do pesquisador ao estudar um determinado problema é verificar como ele se manifesta nas atividades, nos procedimentos e nas interações cotidianas. [...]. O 'significado' que as pessoas dão às coisas e a sua vida são focos de atenção especial pelo pesquisador. Há sempre uma tentativa de capturar a 'perspectiva dos participantes', isto é, a maneira como os informantes encaram as questões que estão sendo focalizadas. (LÜDKE; ANDRÉ, 2013, p. 11-13).
}

Todas essas características da pesquisa qualitativa geram um exercício reflexivo intenso em torno da realidade estudada e paralelamente exigem abertura e flexibilidade dos pesquisadores para lidarem com situações que estão além do planejado, do previsível. Cientes dos limites e das potencialidades dessa abordagem, a clareza que temos é de realizar uma pesquisa com bebês e educadoras no cotidiano escolar, e não apenas uma pesquisa que os coloca como coadjuvantes.

Dito isso, a pesquisa de campo foi realizada em um Centro de Educação Infantil em Ipatinga, uma das cidades do leste de Minas Gerais, reconhecida nacionalmente por contar com uma das unidades da siderúrgica Usina Intendente Câmara (Usiminas). Segundo dados do Instituto Brasileiro de Geografia e Estatística (IBGE, 2018), em 2017, Ipatinga possuía uma população de aproximadamente 261.203 habitantes. De acordo com a Secretaria Municipal de Educação da referida cidade, em 2018, estavam matriculadas 906 crianças em dez creches públicas municipais e 2.575 crianças em 34 creches públicas da rede conveniada.

O Centro de Educação Infantil em questão é uma creche pública municipal, localizada na região central da cidade, que atende a crianças de até 3 anos de idade. Em 2018, ano em que ocorreu a pesquisa de campo, contava com uma turma de bebês

Educação \& Formação, Fortaleza, v. 5, n. 14, p. 115-132, maio/ago. 2020

DOI: https://doi.org/10.25053/redufor.v5i14mai/ago.1647

http://seer.uece.br/redufor 
(sendo dez meninos e quatro meninas) que estavam na faixa etária de 13 a 20 meses quando da observação.

Em relação às quatro profissionais que atuavam com esses bebês, duas eram professoras regentes e duas professoras assistentes da educação infantil, com jornadas de trabalho de 40 horas semanais diretamente com os bebês. Apenas uma das profissionais era efetiva. As demais foram contratadas via processo seletivo. Quanto à formação, duas cursaram o Ensino Normal Magistério de $1^{\stackrel{0}{ }}$ grau e estavam matriculadas no curso de Pedagogia, e duas haviam concluído a graduação e a pós-graduação na modalidade lato sensu. Vale destacarmos que todas as quatro professoras do berçário investigado aceitaram participar da pesquisa, critério que contribuiu para a escolha da creche.

Com esses aceites e autorizações formais da direção da escola, das professoras e dos responsáveis pelos bebês, iniciamos a etapa de observação da rotina no berçário, que durou cerca de três semanas. Para registrar as observações, contamos com dois recursos: o caderno de campo, que nos auxiliou na descrição e na interpretação de algumas cenas; e o smartphone, por meio do qual foi possível realizar as fotografias sequenciadas.

As sequências de imagens produzidas focavam-se em pontos de contato corporal entre professoras e bebês. Quanto ao enquadramento das imagens captadas, utilizamos dois tipos de plano: o "narrativo", com o intuito de capturar duas ou mais pessoas em relação; e o "expressivo", com o propósito de focalizar ainda mais o que se queria registrar, como as expressões e os gestos (ROSATELLI; SPINOLA; MAZZOCO, 2014).

Além dos cuidados técnicos, tivemos a cautela para que as fotografias não se tornassem uma mera reprodução do que vem ocorrendo em nossa sociedade pós-moderna, na qual o viver o presente - o aqui e o agora - parece menos significativo do que a imagem. Registrar cenas do cotidiano fotograficamente foi um rico elemento para a pesquisa: a fotografia que captura cenas, tempos, espaços e acontecimentos passados permite, quando revisitada, ativar a memória e as lembranças. Consoante Rosatelli (2016, p. 7):

[...] o ato fotográfico é um ato cognitivo, criativo e afetivo - tudo ao mesmo tempo -, com a capacidade rara de transformar, tanto simbólica quanto fisicamente, esse espaço. O fotógrafo Henri Cartier-Bresson reforça esse sentido do ver na sua fala emblemática: 'É colocar na mesma mira a cabeça, o olho e a emoção'. 
Entendendo a fotografia nesta pesquisa como uma memória visual e uma linguagem artística, buscamos ajustar nossa percepção interna à câmera exterior, justamente com o intuito de capturar na rotina docente não somente a beleza que se descortina na arte do encontro entre bebês e professoras, mas os ruídos e as faltas, inserindo o que fora capturado em um contexto e cuidando para não isolar o conteúdo.

As imagens produzidas serviram de mediação para os encontros realizados (gravados em áudio e transcritos) em datas agendadas com cada professora individualmente e em períodos posteriores às observações. Para os encontros, as imagens foram organizadas em Episódios (compostos por quatro fotografias sequenciadas) e projetadas por meio do programa Power Point no notebook de uma das pesquisadoras.

A seleção das imagens contou com a participação de uma das pesquisadoras e com professoras participantes da pesquisa. Paralelamente ao período de observação no berçário, organizávamos os arquivos, escolhendo os Episódios que mais convergiam com os propósitos da pesquisa. Nesse processo, separamos fotografias tremidas e/ou com foco ruim. Em momento posterior e individualmente com cada docente, disponibilizamos uma pasta de imagens correspondentes aos registros de interação entre a profissional e os bebês e sugerimos que escolhesse algumas cenas que seriam apreciadas e discutidas nos encontros. Na base da proposta, uma constatação: conversas sobre o corpo pedem passagem na creche.

\section{Vestígios dos corpos nas tipologias de movimentos relacionais aproximados}

Encontros narrativos, como metodologia de investigação, apresentam-se como dispositivos que fogem aos modelos tradicionais de entrevistas, baseados em um roteiro padrão, sustentado pela dinâmica de perguntas e respostas (SOUSA; CABRAL, 2015). Nosso roteiro foi desenhado pela escolha de registros fotográficos produzidos durante as observações. De tal forma, as narrativas orais foram mobilizadas por fotografias da prática pedagógica das professoras, o que pareceu gerar nelas um grande interesse, não somente em compartilhar o vivido, como também em explicar suas intenções e seus desejos, realizados ou não.

Atendendo aos limites de extensão do presente texto, duas sequências de fotografias e os correspondentes registros descritos no caderno de campo serão 
apresentados à discussão. Traremos também a transcrição das narrativas orais de uma das professoras participantes do estudo. Nesse caso, o recorte de dados recaiu sobre dois momentos em que os corpos de adultos e de bebês estavam ao ar livre, em contato com a natureza, no âmbito do parque da creche.

\subsection{Episódio 1: Experimentando texturas e cores na natureza}

Figura 1 - Episódio 1: Professora Michelly com os bebês Gabriel, Davi Correa, Davi Silva, Pedro, Miguel,

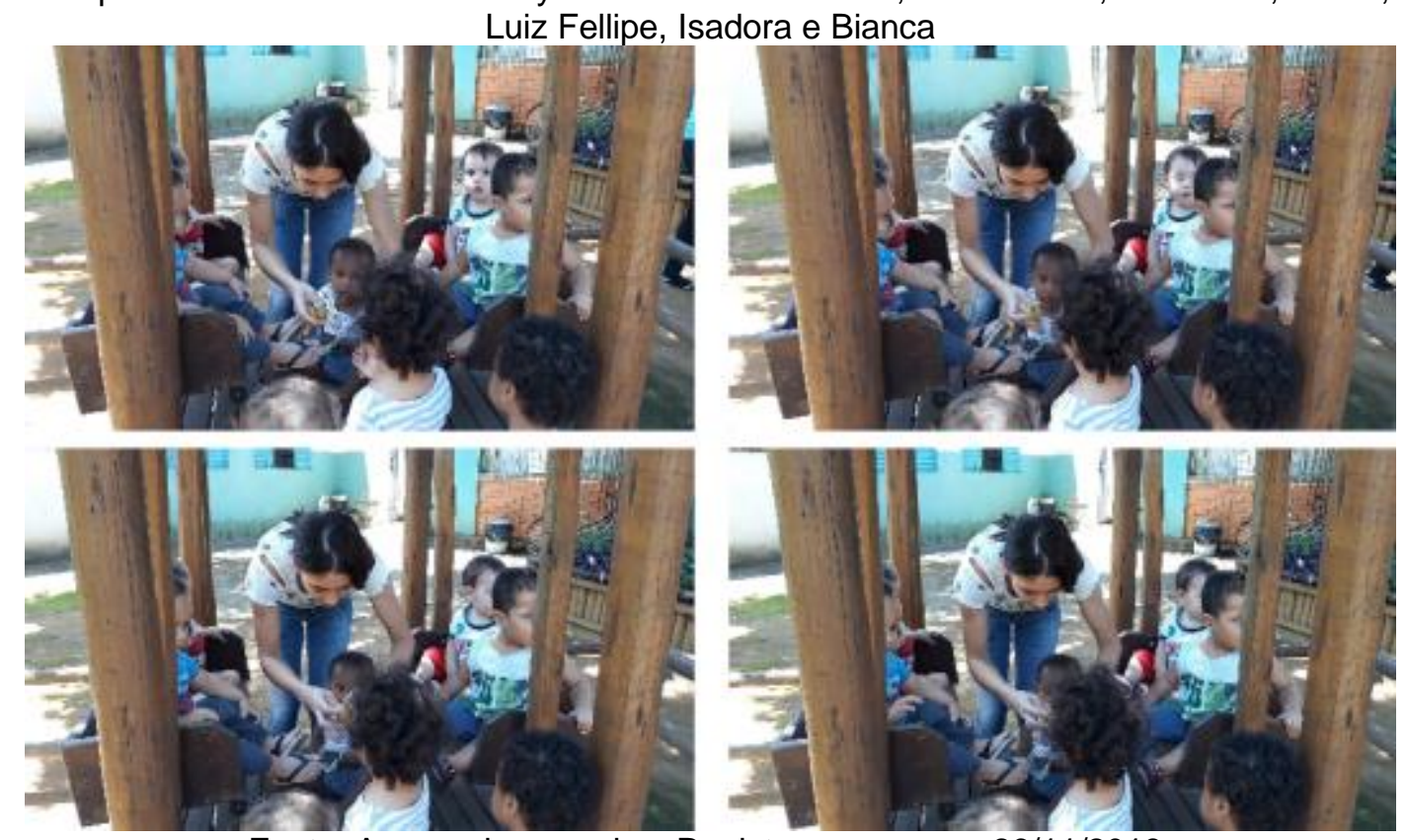

Fonte: Acervo da pesquisa. Registro em campo, 26/11/2018.

Adentramos os espaços-tempos da creche e tivemos acesso a diversos ambientes, um dois quais, localizado na parte externa à sala de referência do grupo, nos pareceu agradar muito aos bebês e às professoras: o parque. Esse espaço ficava aos fundos da creche e permitia o contato com a natureza; contava com brinquedos fixos e móveis, muita areia e árvores que davam sombra. Além da demonstração de apreço por parte dos bebês, talvez por possibilitar maior amplitude dos movimentos e também diversidade nas brincadeiras, o que verificamos é que era um ambiente para aliviar as professoras da rotina que, não raras vezes, se formava entre quatro paredes.

A professora anunciou que eles iriam para o parque da creche. Alguns começaram a tirar os calçados depressa, outros riram e duas meninas caminharam e se assentaram na porta da sala para esperar. A professora Michelly respirou fundo. Parecia aliviada. Normalmente era ela quem dava a maior parte dos banhos nos bebês, que trocava as fraldas (cerca de 70 por dia,

Educação \& Formação, Fortaleza, v. 5, n. 14, p. 115-132, maio/ago. 2020

DOI: https://doi.org/10.25053/redufor.v5i14mai/ago.1647

http://seer.uece.br/redufor 
aproximadamente cinco para cada bebê). Sua rotina era quase sempre no fraldário, uma sala pouco ventilada que ficava nos fundos do berçário. $O$ cargo que Michelly ocupa, de professora assistente, não lhe permitia momentos de planejamento, como ocorria com as professoras regentes. Ao chegarem no parque, Michelly sentou dois bebês em um brinquedo e se acomodou ao lado deles. Fazia movimentos com o corpo para balançá-los. Aos poucos, foram se aproximando do balanço outras crianças. Ela se levantou para que eles se assentassem. Balançou-os. Alguns olharam e sorriram para ela. Michelly retribuiu com um sorriso também. Neste momento, aproxima-se Bianca, uma bebê de 16 meses que entrou na cena e no meu foco, mas que já estava claramente sendo percebida pela professora. Ela traz em suas mãozinhas o fruto da mangueira que havia encontrado no chão. Comunica, por meio de gestos, o que encontrou. Logo em seguida, provoca a atenção de dois outros bebês que se aproximam e também a dos que já estavam no brinquedo. Entrega o fruto à professora, que o recebe, aperta, diz que está duro, que não dá para comer, passa para as mãos dos outros bebês para eles também sentirem a textura. Gabriel repete: 'Está duro'. Bianca retorna ao pé da árvore, pega folhas ao chão, toca na areia, coloca uma das mãos perto do ouvido, como se buscasse escutar melhor um pássaro que cantava. Ela olha para cima, observa. Olha para baixo, procura outro fruto no chão. Quando o encontra, recolhe-o, cheira-o, leva-o à boca. A professora a acompanha com os olhos. Neste momento, ela se volta para Michelly levando o fruto nas mãos. (Registro de observações. Caderno de campo. 26/11/2018).

O acompanhar com os olhos, gestualidade observada entre adulto e bebê na cena descrita, contribui para se entender o que Le Breton (2009) destaca em relação à solicitação do olhar à medida que aumenta o distanciamento nas relações de comunicabilidade estabelecidas. É como se essa atitude suprisse uma ausência corporal entre os sujeitos e, ao mesmo tempo, permitisse a continuidade do diálogo ora iniciado.

Os movimentos e os gestos de Bianca possibilitaram à professora decifrar os desejos da criança e consequentemente perceber o seu próprio corpo, que, raras vezes, parecia se expressar livremente, tendo em vista os movimentos automatizados da sua rotina, como trocar várias fraldas por dia, abaixar-se e levantar-se para limpar os bebês.

Estudos apontam que a linguagem corporal atua potencialmente nas relações interpessoais, fazendo a mediação dos aspectos racional, motor e afetivo, ampliando, assim, a sensibilidade (OLIVEIRA, 2014). A referida linguagem, quando vivenciada na educação escolar, pode não somente favorecer os processos de desenvolvimento e aprendizagem dos bebês, mas o desenvolvimento humano de forma mais ampla. $\mathrm{Na}$ sequência fotográfica gerada, referente ao Episódio 1, e nos registros correspondentes, podemos identificar indícios de aprendizagens e de processos de desenvolvimento: os corpos encontram-se, dialogam e produzem sentidos, mediados pela linguagem acionada pelos gestos do corpo.

Educação \& Formação, Fortaleza, v. 5, n. 14, p. 115-132, maio/ago. 2020

DOI: https://doi.org/10.25053/redufor.v5i14mai/ago.1647

http://seer.uece.br/redufor 
Um gesto pronunciado traz consigo e anuncia outros gestos, pois o corpo carrega muitas histórias, e, "[...] no gesto imediato, vê-se, lá estão, outros gestos a envolver o presente, determinado por gestos passados, que o antecederam e, no agora, indicam e encaminham uma sucessão de outros gestos" (OSTETTO, 2012, p. 126). Isso foi verificado na narrativa da professora durante o encontro:

\begin{abstract}
A gente estava lá no parquinho e estávamos todos no balanço. A Bianca não estava sentada, ela estava em outro determinado local. O interessante é que ela pegou aquele objeto no chão. Ela não sabia o que era e veio até a mim me entregar. E ficou me olhando para tentar identificar o que era, para eu falar com ela o que era. E aí eu falei com ela que aquilo ali era uma manga, mas que não dava para comer, porque ela estava verde, ainda dura! Deixei-os [os bebês] pegarem, ver a textura, segurar, apertar, ver que ela estava dura, que não dava para comer. E eu expliquei para ela: 'Ela está amarela, mas está amarela do Sol, por causa do Sol, ela não dá para comer; ela caiu do pé, mas não dá para comer'. Aí, ela viu, identificou que aquela ali não dava para comer e foi procurar outra. Achou uma outra, levou até a mim de novo. Mostrei para eles novamente que aquela ali também não dava para comer. Aí, como eu percebi o que ela estava tentando fazer, que não era só identificar aquele objeto, mas que ela já conhece aquele objeto e queria comer (no caso a manga), aí, depois, eu procurei, tentei achar em algum lugar se tinha alguma manga que dava para comer. (Registro do encontro em 28/11/2018. Narrativas da professora Michelly sobre o Episódio 1).
\end{abstract}

As narrativas de Michelly confirmam que, por meio de sua observação atenta das expressões, dos gestos e dos movimentos corporais de uma bebê (que, explorando o seu entorno, vai à procura de um elemento da natureza que lhe interessa), a sua ação corporal também se amplia e se mobiliza para outros movimentos, resultando em convidar a $\mathrm{Si}$ e a Outros corpos a verem o parque, a sentirem a natureza, a experimentarem texturas e formas.

Identificamos uma relação estésica, pois compreendemos a estesia como "[...] uma comunicação marcada pelos sentidos que a sensorialidade e a historicidade criam, numa síntese sempre provisória, numa dialética existencial que move um corpo humano em direção a outro" (NÓBREGA, 2008, p. 147). Por meio dos movimentos de olhar, de interagir e de acolher os gestos de Bianca, Michelly busca decodificar os interesses da criança, percebendo o corpo em sua inteireza (WALLON, 2007). Assim, interpreta o que a bebê, sem palavras, diz e vai à procura de uma fruta madura. 


\subsection{Episódio 2: Sabores da natureza}

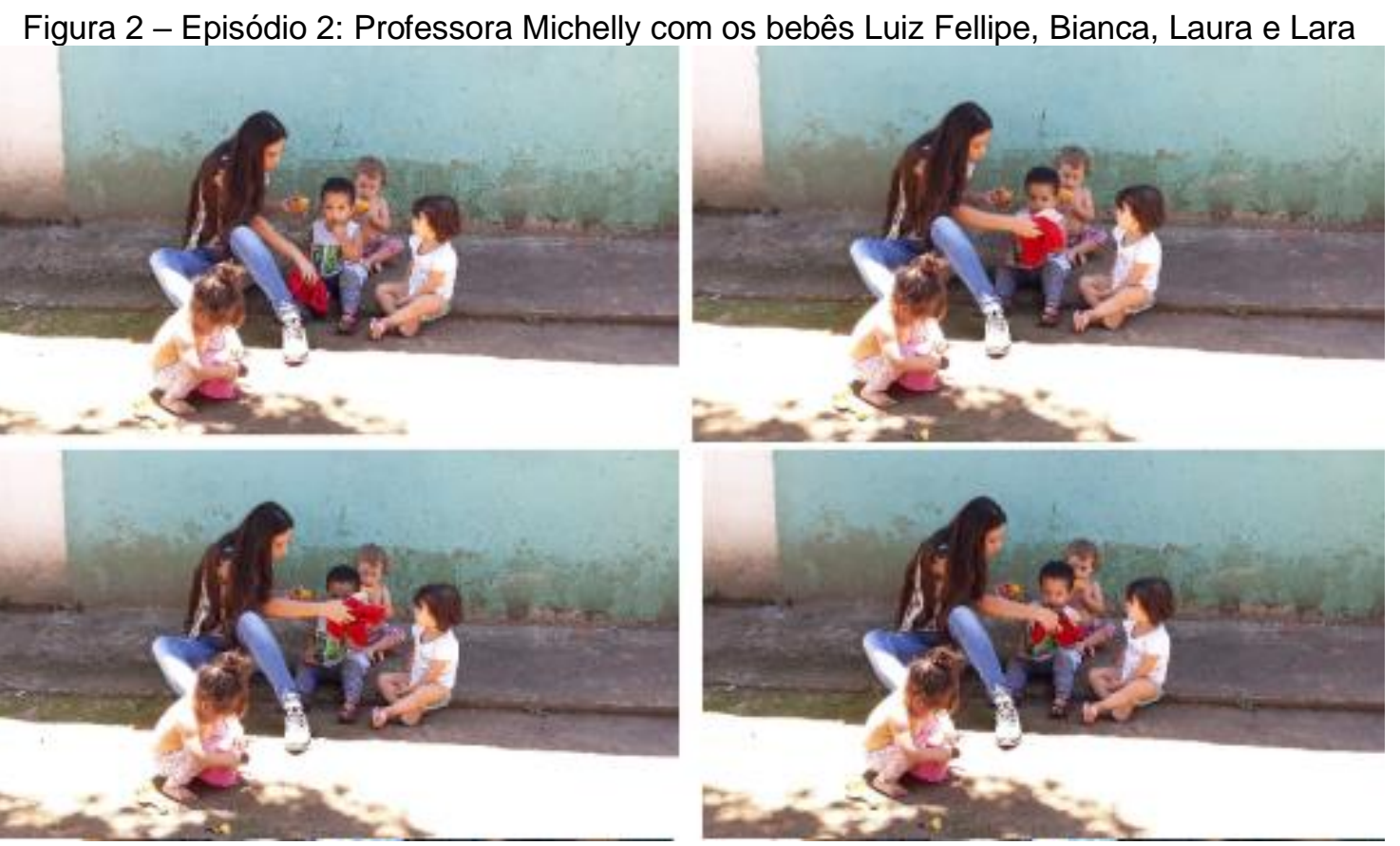

Fonte: Acervo da pesquisa. Registro em campo, 26/11/2018.

Com a boca sentimos o sabor das coisas: o doce, o amargo, o azedo, o suave, o forte. Mas o sabor acorda nossa memória. $O$ gosto do doce de leite traz à lembrança da mãe na beira do fogão e escutamos ainda o ruído da colher raspando o fundo do tacho. O sabor encurta o tempo. Descobrimos que cada gosto guarda uma história. [...]. A boca tem raízes pelo corpo inteiro. (QUEIRÓS, 2009, p. 9-10).

Retomando o poeta mineiro, não é que ele permanece com a razão? A literatura convida-nos a refletir que os sabores, os cheiros, os toques e os sons empurram o corpo para um movimento, que o transpõe do presente para o passado e do passado para 0 presente em velocidade súbita, permitindo que o ser humano que nos habita se reencontre com sua inteireza. $\mathrm{Na}$ análise da leitura corporal realizada na sucessão de sequências fotográficas, percebemos que a atuação da professora foi imprescindível nos dois episódios, pois foi Michelly quem acolheu Bianca por meio do seu olhar, das suas palavras, do valor que deu às sutilezas encontradas no chão pela garota, buscando no diálogo da criança com a natureza novas gestualidades do corpo (PIORSKI, 2016), como podemos observar em sua própria fala:

Essa [sequência de fotos] aí é o momento que ela [a bebê] encontrou a manga, mas não era a manga certa para poder comer. E eu percebi que ela estava querendo para poder comer. Por isso que ela estava à procura. Então, eu procurei, identifiquei, consegui achar uma manga que dava para ela comer. Aí, tirei a casca,

Educação \& Formação, Fortaleza, v. 5, n. 14, p. 115-132, maio/ago. 2020

DOI: https://doi.org/10.25053/redufor.v5i14mai/ago.1647

http://seer.uece.br/redufor 
mostrei para ela, fui lá, lavei a mão dela, porque eles estavam no parquinho, estavam brincando com areia. Limpei a mão dela e entreguei a manga para ela. Eu achei engraçado, porque ela já segurou da forma certa a manga, com as duas mãozinhas, e já a levou a boca. Então, através disso, eu já entendi que ela já conhece. Alguém em casa já deve ter mostrado para ela alguma coisa assim, e ela já identificou que aquele objeto ali ela pode comer, que aquela fruta dá para comer, que é uma manga. E o engraçado é que ela estava sozinha. Eu a peguei, a trouxe e a deixei sozinha. Que só ela identificou que aquilo ali poderia comer. E os outros já não identificaram. Para eles, é só um objeto, não sabem o que é; não sabem identificar. Aí, como eles viram que ela estava comendo, eles se aproximaram, até mesmo para descobrir, ver qual é a textura, ver qual é o sabor. Então, eles chegaram próximo e eu os deixei pegarem também para perceber, aprender. (Registro do encontro em 28/11/2018. Narrativas da professora Michelly sobre o Episódio 2).

No desenrolar das narrativas corporais entre Bianca e a professora, Luiz Fellipe, o mesmo bebê que compunha o Episódio $1 \mathrm{com}$ a menina, parece interessar-se pela fruta, acompanha a professora com os olhos, chega até ela e busca expressar que também quer saborear a manga. É interessante notarmos, sem atribuir juízo de valor, as marcas da cultura ocidental, da visão higienista, como, por exemplo, a preocupação da professora em lavar as mãos da bebê para degustar a manga. Notamos ainda um jeito peculiar de segurar a fruta, que a professora enfatiza como a "forma certa". Isso vai ao encontro do que dissera Le Breton (2012a, p. 8): "Os feitos e gestos da criança estão envolvidos pelo padrão cultural (ethos) que suscita as formas de sua sensibilidade, a gestualidade, as atividades perceptivas, e desenha assim o estilo de sua relação com o mundo". Em suma, o que pudemos perceber é que a bebê Bianca provocou a gestualidade da professora e a de outros colegas, tornando-se protagonista de vivências ricas e desafiadoras na creche.

\section{Na natureza, possibilidades de relações corporais expandidas}

Assim como nos dois movimentos básicos de respirar - 0 de inspiração e o de expiração -, nos espaços e nos tempos da creche, os movimentos corporais, de adultos e de bebês em relação, expandem-se e contraem-se. O que pudemos observar nas tipologias de movimentos relacionais aproximados, presentes nos episódios registrados ao ar livre, é que a qualidade da relação estabelecida entre professora e bebês foi fundamental para a descoberta do corpo na experimentação do espaço, das texturas, das formas e do sabor e também para a compreensão dos gestos como linguagem. 
Não menos importante a considerarmos é que a natureza pode possibilitar aos que dela usufruem experiências e percepções mais intensas e vibrantes do corpo, o que pôde ser notado em movimentos como olhar para o céu e para o chão, ouvir o pássaro, pegar a folha, tocar na areia, sentar, colher, acolher e compartilhar. Não seriam esses ricos processos de aprendizagem na escola?

Retomando à questão inicial da pesquisa - "Que narrativas sobre/com o corpo são tecidas em um berçário considerando-se as relações entre adultos e bebês no cotidiano educativo?" -, concluímos, ainda que provisoriamente, que a relação aproximada estabelecida entre professora e bebês nos espaços-tempos do parque foi acolhedora, espontânea e expressiva, visível nos gestos, nos olhares, na interpretação dos movimentos dos corpos.

Um olhar atento para a linguagem do corpo nesta pesquisa traz contribuições para pensarem-se as práticas na educação infantil, em especial as práticas educativas para as crianças de 0 a 3 anos nas creches. Em primeiro lugar e parafraseando Le Breton (2012b), os lugares onde se educam interferem diretamente nos processos de sociabilidade humana e de percepção do corpo. Em segundo lugar, bebês, em contato com a natureza, provocam nos adultos o interesse de aterem-se às sutilezas, a pensarem em outros formatos de educação e em temporalidades que privilegiem a vivência de todos os sentidos, corpo inteiro. Em terceiro e último lugar, uma percepção atenta para a linguagem do corpo auxilia professoras e professores a olharem para $\mathrm{Si}$, um movimento que, para os nossos dias, é fundamental, pois: "O fluxo do cotidiano, com suas escansões costumeiras, tende a ocultar o jogo do corpo na apreensão sensorial do mundo ambiente ou nas ações realizadas pelo sujeito" (LE BRETON, 2012b, p. 156).

\section{Referências}

ALMEIDA, L. R. A questão do Eu e o Outro na psicogenética walloniana. Estudos de Psicologia, Campinas, v. 21, n. 4, p. 595-604, 2014.

BRASIL. Constituição de 1988. Constituição da República Federativa do Brasil. Diário Oficial [da] República Federativa do Brasil, Poder Executivo, Brasília, DF, 5 out. 1988. 
BRASIL. Lei no 9.394, de 20 de dezembro de 1996. Estabelece as Diretrizes e Bases da Educação Nacional. Diário Oficial [da] República Federativa do Brasil, Poder Executivo, Brasília, DF, 21 dez. 1996.

BRASIL. Resolução CNE/CEB no 5, de 17 de dezembro de 2009. Fixa as Diretrizes Curriculares Nacionais para a Educação Infantil. Diário Oficial [da] República Federativa do Brasil, Poder Executivo, Brasília, DF, 18 abr. 2009.

CAMARANO, A. A.; KANSO, S.; ALCÂNTRA, V. S. Desigualdades na dinâmica demográfica e as suas implicações na distribuição de renda no Brasil. In: CAMARANO, A. A. (Org.). Novo regime demográfico: uma nova relação entre população e desenvolvimento?. Rio de Janeiro: IPEA, 2014. p. 241-270.

CAMPOS, M. M. M.; CRUZ, S. H. Consulta sobre qualidade da educação infantil: o que pensam e querem os sujeitos deste direito. São Paulo: Cortez, 2006.

IBGE - Instituto Brasileiro de Geografia e Estatística. Dados de Ipatinga. Rio de Janeiro: IBGE, 2018.

LE BRETON, D. A sociologia do corpo. 6. ed. Petrópolis: Vozes, 2012a.

LE BRETON, D. Antropologia das emoções. Petrópolis: Vozes, 2019.

LE BRETON, D. Antropologia do corpo e modernidade. 2. ed. Petrópolis: Vozes, 2012b.

LE BRETON, D. Antropologia dos sentidos. Petrópolis: Vozes, 2016.

LE BRETON, D. As paixões ordinárias: antropologia das emoções. Petrópolis: Vozes, 2009.

LÜDKE, M.; ANDRÉ, M. E. D. A. Pesquisa em educação: abordagens qualitativas. 2. ed. São Paulo: EPU, 2013.

NÓBREGA, T. P. Corpo, percepção e conhecimento em Merleau-Ponty. Estudos de Psicologia, Natal, v. 13, p. 141-148, 2008 . Disponível em: http://www.scielo.br/scielo.php?script=sci_arttext\&pid=s1413-294x2008000200006. Acesso em: 20 mar. 2020.

OLIVEIRA, N. R. C. Infância, corpo e movimento: notas para (re)pensar os tempos e espaços na educação infantil. In: OLIVEIRA, W. C.; DAMIANO, G. A.; PEREIRA, L. H. P. (Org.). Corporeidade, educação e tecnologias: experiências, possibilidades e desafios. Jundiaí: Paco, 2014. p. 106-120.

OSTETTO, L. E. Dos gestos na educação infantil: textos no corpo. In: OSTETTO, L. E.; LEITE, M. I. (Org.). Arte, infância e formação de professores. 7. ed. Campinas: Papirus, 2012. p. 121-128. 
PIORSKI, G. Brinquedos do chão: a natureza, o imaginário e o brincar. São Paulo: Peirópolis, 2016.

QUEIRÓS, B. C. Os cinco sentidos. 3. ed. São Paulo: Global, 2009.

ROSATELLI, L. A. C. Prefácio: o olhar seguro $x$ o olhar experimental. In: GRUPO MARISTA, Rede de Solidariedade (Org.). Territoriar: relatório de percurso formativo: registro fotográfico. Curitiba: Champagnat, 2016. p. 6-7.

ROSATELLI, L. A. C.; SPINOLA, A.; MAZZOCO, B. Como fazer registro pedagógico em foto e vídeo. 2014. Disponível em: https://novaescola.org.br/conteudo/1882/registrosque-fazem-o-professor-refletir-sobre-a-pratica. Acesso em: 5 fev. 2018.

SOUSA, M. G. S.; CABRAL, C. L. A narrativa como opção metodológica de pesquisa e formação de professores. Revista Horizontes, Itatiba, v. 33, p. 149-158, 2015. Disponível em: https://revistahorizontes.usf.edu.br/horizontes/article/view/149. Acesso em: 20 mar. 2020.

WALLON, H. A evolução psicológica da criança. São Paulo: Martins Fontes, 2007.

WALLON, H. Psicologia e educação da infância. Lisboa: Estampa, 1975.

Patrícia Vieira Bonfim (Niterói, Rio de Janeiro, Brasil)
Universidade Federal Fluminense (UFF), Programa de Pós-Graduação em Educação,
Doutorado em Educação
Doutoranda em Educação pela UFF. Pedagoga no Instituto Federal de Educação, Ciência e
Tecnologia do Sudeste de Minas Gerais - campus Muriaé. Membro do Círculo de Estudo e Pesquisa
Formação de Professores, Infância e Arte (FIAR).
Contribuição de autoria: Produção dos dados (registros fotográficos, gravação em áudio, transcrição e
notas em caderno de campo), organização preliminar do referencial teórico, delimitação da categoria
de análise tomada para foco no artigo e elaboração da versão inicial do texto.
Lattes: http://lattes.cnpq.br/0490029520812954.
E-mail: patricia.ftbp@gmail.com.

\section{Luciana Esmeralda Ostetto (Niterói, Rio de Janeiro, Brasil) \\ Universidade Federal Fluminense (UFF), Programa de Pós-Graduação em Educação, Faculdade de Educação}

Doutora (2006) em Educação pela Universidade Estadual de Campinas (Unicamp) e mestra (1992) em Educação pela Universidade Federal de São Carlos (UFSCar). É professora da Faculdade de Educação da UFF, onde atua na pós-graduação (mestrado e doutorado em Educação) e na graduação (curso de Pedagogia).

Contribuição de autoria: Orientação na metodologia da pesquisa, colaboração na análise dos dados e revisão do conteúdo, com proposição de adensamento teórico e ampliação do manuscrito.

Lattes: http://lattes.cnpq.br/7470127128501920.

E-mail: lucianaostetto@id.uff.br.

Editora responsável: Lia Machado Fiuza Fialho Pareceristas ad hoc: Michelle de Freitas Bissoli e Joceane da Silva Machado 


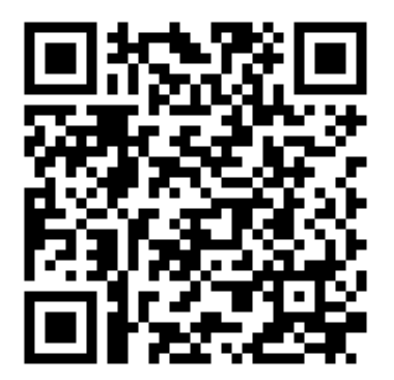

Recebido em 08 de setembro de 2019.

Aceito em 29 de janeiro de 2020. 